\title{
Intersectionalities, dis/abilities and subjectification in deaf LGBT people: An exploratory study in Sicily ${ }^{45}$
}

\author{
Claudio Cappotto \\ Frederic II University of Naples \\ Cirus Rinaldi \\ University of Palermo
}

\begin{abstract}
The article discusses the multiple discrimination, normalization and stigmatization experienced by deaf LGBT youth in Sicily, Italy, on the basis of a study of their everyday life (specifically school years and peer interactions). So far in Italy, very little attention has been paid to multiple discrimination and, specifically, to homophobic violence towards disabled individuals. It is, therefore, impossible to consider any valid sampling of the desired population and very few reports have been produced. The authors, a sociologist and a psychologist, carry out an analysis of the results obtained from interviews with 15 LGBT individuals recruited through social networks, thematic chats, and associations. This preliminary analysis aims at identifying the key arguments which could form the basis for future strategic inclusion programs and further research projects.
\end{abstract}

Key words: LGBT youth, disability, homophobia, normalization, intersectional analysis

\section{Introduction}

The present essay sums up the results of research carried out in the south of Italy (Sicily) regarding the problem of discrimination against deaf LGBT people. This is, in fact, a preliminary analysis aimed at identifying key arguments which could form the basis for possible future strategic programmes, with the objective also of further exploring the research themes that emerge and of expanding the sample population to reach statistically relevant dimensions. There are at present no statistically relevant studor research, at least in the Italian context, with regard to the multiple discriminations suffered by the deaf LGBT population. The only data available is extrapolated from various grey areas of literature and unpublished research reports carried out by third-sector and volunta ies ry associations. The very concept of multiple discrimination is open to many contrasting

${ }^{45}$ This paper is co-authored and as such stems from a joint reflection. Cirus Rinaldi edited sections 1, 2 and while Claudio Cappotto wrote sections 3 and 4 . The conclusions are to be accredited to both. 
interpretations which can be difficult to apply. A certain group or a social category might be discriminated against for different reasons or because of diverse characteristics which coexist simultaneously (for example an illegal immigrant who is also homosexual) or in different periods (a homosexual who has become disabled); and either for inherent conditions (a deaf homosexual) or for subsequent ones (a deaf person who discovers his/her homosexuality). In this way the same conditions may have been present since birth, they may coexist, or they may even interfere with each other. Therefore it is clear that these stigmatized social groups or categories are liable to suffer various types of discrimination that in many cases can also be multiple. For example, the access to housing assistance (public or private) of a lesbian couple could be inhibited not just by the obviousness of the relationship between them but also by social prejudice and by legal difficulties relative to the lack of freedom for homosexual couples to express publicly and legally their intimate choices concerning cohabitation and relationships (at least in Italy). We could, for example, imagine a situation where one of the partners is from a different ethnic background, and predict her difficulty in obtaining employment; moreover, she might simultaneously suffer gender discrimination as she is a woman. Our hypothetical couple might be discriminated against because they are lesbian, or because they are mixed race, or again because of gender (being female). It is possible to imagine a case of a person stigmatized for his sexual orientation - a male homosexual who is also deaf. As we will demonstrate below, this person could find himself isolated in the queer world, and also be discriminated against should he dare to express a desire for paternity, not only because he is homosexual but also as he might be considered an unsuitable father on account of his disability. He would then find himself doubly isolated: inside the queer world and within the conventional world. We could, of course, also imagine social situations in which there is no multiple discrimination in the strict sense of the term, but instead subtle forms of discrimination regarding various prevailing elements and secondary features and traits of the group or person concerned. But how can we construct a hierarchy of the diverse potential and concrete factors of discrimination? From a theoretical point of view, the concept of multiple discrimination is insidious precisely because anti-homosexual and anti-transsexual prejudice is not just deeply rooted in popular culture but it becomes a reason for discrimination even inside the LGBT community. This factor induces us to reflect critically about the way "discrimination" can be defined as "multiple" on the basis of which group or category the subject belongs to, in accordance with the biophysical characteristics of the individual and of his/her physical dis/abilities, gender, ethnic group and social status. It is therefore implausible to give a conceptual definition of the term "multiple discri- 
mination" except in the open and flexible form provided here, and to confront with rigid social structural concepts the actual multiple involvements of individuals and social groups, their individual characteristics and the diverse combinations between these functions. Let us not imagine any definitive unalterable definition of "multiple discrimination", bearing in mind that it is necessary to always address the context of these discriminations and consider the historical, social, cultural, political, legislative and even "local" processes and developments.

Nevertheless, in methodological terms and following a meta-sociological deliberation, the issue of multiple discrimination provides opportunities for general theoretical reflection on the topic of the social construction of identities and the sense of belonging to a particular group or groups, even within the scope of a wider analysis of the various LGBT movements and factions. Also in light of the empirical data that will be collected, a new interpretation will be presented with reference to the problems regarding the sociological perspectives of the analysis of the queer community and the notion of intersections (Collins 2000). These are hypotheses that refuse every attempt at simplification, and demand a proper comprehension and a critical interpretation of the processes of normalization of violence and of discrimination against the LGBTQI community and also of the "normalization" of the above-mentioned forms of subjection. Analyzing the intersections and consubstantiality between genders, sexual orientations and physical (dis)abilities enables us to highlight how subjectivities are defined based on specific structural aspects with which the dominant heterosexual and heteronormative power system rules and governs (Warner 1993). Meanwhile, the filter of queer sociological analysis allows us to identify the risks of perpetuating within representations of the LGBT community a "normalization" model that imposes new forms of corporeal stratification and subordination systems.

\section{Anti-identitarian marginalities: Intersectionalities, physical disabilities and}

\section{sexuality}

The dominant sexual categories (the homosexuality/heterosexuality dichotomy) and the structures of power continue to hold a place of privilege. They are normalized, naturalized or forgotten in the double significance of having become the norm and being taken for granted, because they are both grounded in a single and totalitarian story of "fixed views". Likewise, for example, whiteness, heterosexuality and even able-bodiedness are socially constructed as being the dominant, normalizing (with the double meaning of the statistical norm and of the normal moral virtue) and 
as such universal social institution. The co-existence of the male/female dichotomy system, the forced attribution of heterosexuality as a universal sexual orientation and the imposition of identity (whether homo or hetero) is particularly evident in the diagnostic and medical-surgical-cultural treatment reserved for subjects outside the norm, but it becomes a hierarchal imposition even when defining a disability, with the aim of constructing normal subjects. These issues have still to be implemented within the scope of a sociological research programme that must take into account the instability and arbitrariness of the categories used and of the divisions defined by these categories (such as the homosexual/heterosexual or able bodied/disabled divide). Then we also need to consider the conceptual inadequacy of the construction of identity (be it homo or hetero) as a static, ahistorical and anti-social dimension, as well as the effects in the real world of any "scientific" programme, measure or service. The universalistic ideal that defines the citizen has, in fact, excluded all these subjects from citizenship, as their existential, expressive and affective needs do not fit in well with the abstract, neutral and universal structure represented by the state. We could argue that the state has situated corporealities on an aesthetic axis that effectively legitimizes the denigration and humiliation of certain bodies (women, immigrants, lesbians, gay men, the disabled, etc.) that do not conform to the norm. If, on the one hand, minority movements - and especially the LGBT movement - have contributed to the inclusion of homosexuality in the public debate, on the other hand, they have ended up normalizing homoerotic desire, highlighting the extent of the discrimination (especially of male white homosexuals) and defining a quasi-ethnic identity within subcultural theories. The main effect of the theories was to stall the debate on the social construction of heterosexuality and the cognitive divide deriving from the heterosexual/homosexual dichotomy (Murray 1979), but also and above all to define homosexuality as a universally applicable identity category, and of a uniform and pure identity. This refers to the construction of methods of desirability and sexual subjections, to the types of legal claims (requests which are considered high compromises from a heterosexual point of view, but which are often inadequate for many of us LGBTs) the normalization of what is different which translates into forms of (male) heterosexualization of homosexuality, with specific relapses (both theoretical and in terms of policies) connected to the annulment of the different intersections between gender, ethnicity, social status, sexual orientation and physical (dis)abilities among others. Scholars who study the queer scene regard the analysis of the knowledge deriving from the cognitive mechanism represented by the heterosexual/homosexual dichotomy and by the categorization of identities as an essential element. The homosexual/heterosexual binary has structured social awareness 
throughout the late $19^{\text {th }}$ century. This control mechanism has worked by establishing classification systems which sort people by type of body, of personality and human subtype, but also by other aspects such as the organization of knowledge, of social life, and of expectations and ways of thought regarding human relations (Ingraham 2005) and the public debate regarding "unnatural" sexualities. Every desire and practice, just as every hypothetical form of "belonging", has been described in minute taxonomic detail with regard to the choice of the desired sexual object on the basis of the usual homosexual/heterosexual dichotomy; yet a major part of the types of human subjectivities cannot be reduced to, or included in, these counter-positions.

From the standpoint of the political practices relating to scientific papers, we can consider that queer cognition allows us to understand experiences that concern subjectivities outside the norms from within their social world and through their own "categories". An extra dimension has been provided through the methods and methodologies of the feminist movement which repositioned women as sexual beings, while working as researchers or co-researchers within a research team. Queer scholarship is thus inclined to question the methods of scientific research that serve to identify and reproduce "normal" and standard bodies, genders and sexuality.

Queer methodologies are political insofar as the emancipation of individuals outside the norm actually starts with the use of a new vocabulary which is capable of taking the floor. In fact in the very instant that a subject is represented as "deviant", that person becomes liable to be labelled and questioned as such, the same label is applied and reapplied and becomes an implicit form of monitoring, control and identification. In order to escape imposed denominations and overturn theoretical and "ontological" boundaries, one must create and use a customised lexicon which allows one to define oneself in terms which transgress conventional boundaries. The issues affecting the queer subject, which are in many ways similar to the ones confronted by the postcolonial subject, should raise awareness in researchers and help them to navigate these lexical boundaries, question the hypothetical and spatialized interpretation of these categories, and confront said categories and spaces - in other words, to de-centralize. Living on the edge of the dominant identity structures (heterosexuals or homosexuals) and thus inside a wider society which includes the able-bodied, the LGBT community and activists and pressure groups involved with disability issues - with consubstantiality between diverse types of belonging, which confront in the case of physical disability the hierarchies of physical stratifications (at the pinnacle of which stands 
the heterosexual or homosexual white middle-class and physically fit male); they challenge the concept of identity and belonging (the community aspect). Discussing the theme of identity hybridizations and of their simultaneous co-existence (black gay bodies, Afro-Italian transgendered bodies, deaf LGBT Asian-Americans, etc.), Rosanne Bersten argues that identity as such is a dangerous concept and that there are other patterns of identity formations relating to the definition of minority communities that are equally problematic (Bersten 9). Every identification process is imperfect, no group is ever homogeneous, and the individuals involved, argues Bersten, do not perform perfect identities, as identity processes are often recurrent, and each time the process commences anew, a new degree of fragmentation is added into it (Bersten). In the case of hybrid and intersected identities, theories focused on the notion of identity contribute to reinstating the myth of identity essentialism and ultimately allow edge identities no more than three viable options: to abandon their own traditional practices with a view to accepting a constructed self seen as preferable and legitimate within the scope of specific interpretative communities; to learn to blend in, chameleon-like, adapting themselves and their personal identities to fit into whichever group they wish to belong; or lastly, to attempt to re-territorialize a community which rests on minority identity models. Focusing on material practices rather than on taxonomic identification enables us to consider the risks of universalizing and of neutralizing disabilities; these analyses allow us to understand the intersections between the workings of power that humiliate and those that oppress, between the construction of aesthetic ideals, between sexual and identification categories and assimilated subjects (Muñoz 1999; Anzaldúa 2007). This involves performing a circumstantial analysis of the areas of tension, stitches and scars, rather than on the coherence of any configuration of identity (Bérubé 2006). Under these criteria, a queer analysis of disabilities enables us to understand how in late capitalist and neoliberal society, individuals are obliged to be both able-bodied and heterosexual (McRuer 2006). In strictly sociological terms, the intersections can converge in simultaneous axes of subordination and multiple dimensions of oppression, demonstrating how the very concept of disability does not apply to an individual problem (or simply a medical condition) but rather is a social and collective experience (Thompson, Bryson, and de Castell 2001, 51). In fact, stereotyped depictions of disabled people and disability can cause the actual experiences of a person to become distorted: the myth of bodily perfection in which the disabled clash with the able-bodied; the myth of the asexuality of the disabled; the stereotypes linked to sexual orientation and regarding the effects of heterosexualization (if someone is disabled there is the presumption of asexuality but if various drives or desires should 
manifest themselves, these drives can only be heterosexual ones according to the beliefs of doctors and social workers), thereby making emancipation more complicated for the disabled. A web of social inhibitions controls non-normative sexuality and usually the sexuality of the disabled as well, because they are considered subjects who could lose control at any minute (Thompson and Bryson 59). In light of the feminist, constructivist and queer research perspectives, sociological reflection should direct its analyses towards the deconstruction of the universal and naturalizing expectations of able-bodiedness (McRuer 1).

\section{Studying multiple discrimination through microsociological applications}

As regards social interactions in everyday life, processes of normalization refer to all those rituals that individuals use to control their own behaviour in order to appear normal, or to those practices which in one way or another cause people to re-evaluate and change behaviours, conditions or attitudes that have previously been stigmatized (Goffman 1963). Within the scope of microsociological analysis, the concept of normalization should be analysed considering the processes which lead to question social expectations (deviance) as well as consequent blame and normalization mechanisms such as stigmatization processes. The social interaction order is therefore built on a perception of trust based on normal appearances and actions that contribute to its foreseeability, reliability and interpretation (Goffman 1959). Social actors are constantly involved in normalcy-constructing processes, based on which they routinely elaborate and experiment with everyday interactions. The very definition of normalcy is based on reproducing and reinforcing these routine normalcy practices which are embedded in individuals as a form of tacit knowledge, necessary to convince oneself - and especially others - that everything is "exactly as it should be". Thus we find ourselves involved in activities that have the ultimate purpose of enabling us not to lose face by reproducing the (legitimate) order of appearances and normalcy, Goffman suggests (1971). Such activities are in fact categorized and become constitutive of "normal" experience; in this way the representation of normality and its orderly construction become collective activities supported by ritualistic interactions. Whenever a certain behaviour (or a characteristic, a habit, a personality trait, etc.) is perceived and considered as inappropriate for the circumstances, this challenges the normal smooth running of events and occurrences and provokes others to feel that something must be done to ring back under control or to remedy and there is someone who needs to be adjusted. The processes of stigmatization can be interpreted as tools used by normal people to highlight the abnormality of others who possess alarming personality traits, 
conditions and characteristics, with the aim of reverting everything back to the norm, if that is possible - such as in the cases of juvenile delinquents, and drug addicts inside a rehabilitation centre, of disabled people who need to be "fixed". The concern with normality and the need to appear normal, because of the need to maintain order and legitimate it, thus becomes an objective even for the very people who are stigmatized. This situation leads us to reflect on how normality is really a precarious condition, which has to be continually renegotiated through performances aimed at making the individual seem reliable and pass off as normal. These theoretical premises seem particularly important when referring to groups with a stigmatized status, either identifiable or already identified, such as LGBT people with a dis/ability, who are liable to be discriminated against due to their invisible membership of stigmatized groups. Cramer and Gilson identify a series of existing analogies between groups belonging to sexual minorities and groups of disabled people: they often see their own civil rights go unacknowledged, and they live in constant tension between choosing to declare themselves and then putting up with a stigma (because of their sexual orientation or their disability) or to conceal these facts, choosing evasion and thus passing for nondisabled and heterosexual (Cramer and Gilson 1999, 26).

\section{The research design}

As mentioned above, the present analysis focuses on data gathered in a specific setting (Sicily) in 2010. It has not been possible to take into account a statistically representative sample both for reasons of social advisability (the LGBT deaf community being already victims of a double stigma) and due to the difficulties that arise in the recruitment of LGBT deaf individuals, which would have involved a greater investment of resources and time. We therefore utilized as our first point of contact a gay LIS (Italian Sign Language) interpreter who enabled us to access the desired target group (by accompanying him during an interview with a group of LGBT deaf subjects), some remote contacts (chat) and also the publication of a video containing a questionnaire specifically designed for the purposes of this research and indicated in LIS (see http://www.youtube.com/watch?v=KGI3CAqy_Ko). Thanks to our LIS interpreter contact we were able to involve the associated network (Deaf LGBT Group of Sicily) who graciously agreed to take part in the research activities. (Though later some of the subjects showed diffidence towards us, this was overcome thanks to the intervention of the LIS mediator.) We managed to recruit 15 LGBT deaf subjects (6 of whom defined themselves as lesbians, 6 others as gay and 3 persons who described themselves as bisexual; average age 24.5 years). Among this group, five people returned 
the completed questionnaire via email, four were interviewed as a group with the help of the LIS interpreter, and the remaining six were contacted by the researcher through social networks and chats (Facebook). As described above, the search for and the involvement of LGBT deaf subjects brought about certain difficulties, mostly due to the difficulty in recruitment but also to more technical problems regarding the administration of the material and the written correspondence. As one of the interviewees - the promoter of the Deaf LGBT Group of Sicily associated network claims, "for some deaf people these are questions that they cannot answer . . . these are long questions and deaf people are not usually able to give long-distance replies with long sentences" (Interview M., gay male, aged 22, chat on $26^{\text {th }}$ May 2012). In this respect, the difficulties with the deaf population regarding recruitment and provision of social research material is heavily conditioned by their level of education, and their knowledge of written and sign language, apart from other more general socio-economic and cultural factors. Having overcome the initial resistance of some subjects included in the sample, and having dealt with the problems connected to the lack of suitable mechanisms of social appraisal necessary for the analysis of the needs of the deaf population, it has been particularly helpful to agree on a critical and highly sensitive approach to the LGBT deaf culture. In fact, as one of the homosexuals contacted via chat (R., lesbian, aged 26, from Caltanissetta) explained, "usually the deaf are wary of strangers. They wonder why a doctor whom they do not know is collecting questionnaire .... at times we feel like guinea pigs".

\section{Data analysis}

The people interviewed were asked to discuss their school years and their everyday life in order to consider the main challenges faced during youth. The intervieews have, for the most part, attended mainstream state schools and only later on in their learning pathway chose to attend special schools. Within their educational and family context, they complain of the lack of socialization to the rituals, customs, norms and rules of behaviour that their orientation involves (but this logic can be extended in order to include every type of erotic-affective exchange); and declare to have lived, especially during the period of mandatory schooling, in prevalently heteronormative and normal surroundings, which lead to the lack of a proper vocabulary with definitions they could use to describe themselves as LGBT and deaf individuals. In this way, a majority of these subjects have associated deafness and homosexuality as aspects which caused unease and discrimination during their upbringing, education and social life. M. states that while she was in the middle of her secondary education, she could not manage to "lip-read the literature teacher." "The professor, 
when he explained things or asked me questions, talked to the left or right of me or turned his back to me, and when he had finished, he still expected an answer from me. I could not manage to get a single word that he said, although I studied a lot and would certainly have answered his questions if only he had let me understand them." As far as her homosexuality was concerned, she never managed to talk about it or confide in any of her peers (M., lesbian, aged 20).

The double stigma of deafness and homosexuality is particularly emphasized in the words of N.: "I attended mandatory state schools from the age of 3 to 13 and I was the only deaf person there. These were years in which I suffered a lot. Already in the very first years of my life I felt misunderstood for two parallel reasons - for my deafness and for my sexual orientation. I remember that I felt sorry for myself, and often thought that I was different, unique, that there was nobody else like me, and above all, I thought that it would be impossible to find good social occasions and professional opportunities in the life of a deaf person. I had these thoughts daily because as a deaf person with homosexual tendencies I had consistent negative experiences with almost all my classmates" (N., lesbian, aged 25). The same difficulties are mentioned by S., who claims: "my relationships with my classmates were not good, especially when I attended secondary school. There were negative events that left me feeling very low. I remember that as soon as I got home I would burst into tears. This was all because of people's ignorance. They would tease me, calling me handicapped or homosexual. Back then, I hadn't yet come out as a homosexual" (S., gay male, aged 25).

R. also experienced the impact of this double stigma both at home and in school: "I attended mainstream state schools with normal-hearing people. In primary school I had the best teacher in the world. She knew how to handle my condition and always took great pains to make sure I was taught properly. Then, in secondary school, I had to deal with teachers who completely neglected my handicap, and it was a hard blow. A few teachers were particularly bad as they didn't even want to show me their lips when they spoke. One would speak with his back to me, and the other one had a long moustache that covered his whole mouth and which he always refused to trim for my sake, despite my parents' protests. In middle school, on the other hand, I received the necessary care and attention and performed well academically. I was happy and I had a big crush on my math teacher. I would often bring her up in conversations with my mum. Then my mum grew jealous of her and one day she scheduled a meeting with her and told her I was in love with her. I was really 
crushed. I felt that my mum had betrayed my trust and I felt so ashamed to have these feeling which before I had experienced as good, for my teacher. I was never able to look her in the eye after that" (R., lesbian, aged 22).

It would be difficult for the people we interviewed to see themselves in a global dimension. As Goffman remarks, people with a particular stigma tend to have the same cognitive experiences as far as their minority problem is concerned. We see analogous changes in their self-perceptions, and a similar "moral career" which is both a cause and effect of their need to undergo every stage of adaptation in similar ways. One of the phases of this socialization process is that through which the stigmatized person learns to interiorize the points of view of normal people, thereby acquiring the belief system that the wider society has on identity questions as well as a general idea of what it means to have a particular stigma (Goffman 1963, 68). The construction of an identity and of a common language and rituals occur outside the regular processes of socialization and the majority of the subjects have attributed the reasons for their own discomfort to the reactions of the people closest to them (family and peer group). The main reasons for suffering could therefore be found in a sort of loosening of relationships within a social context. This separateness from the drama of close connections is determined, in the opinion of the participants, by the non-belonging to a community or group that is immediately visible and can be clearly distinguished, and also by the non-possession of a shared and current repertoire of symbolic rituals both easily accessible and transferable, to the contrary of what is to be found in the hearing and heterosexual community which has access to reference models. The possibility of using a shared symbolic/cultural reference system is considered an essential resource, not only with regard to all those factors that can be brought back within the notion of social inclusion but also to assist the orientation of behaviour in the various contexts of daily life and interaction.

One of the contradictory issues that emerged from the discussion with respect to the discomfort of not belonging is the difficulty the subjects had to feel part of a group or community: the reasons given by these individuals for strategically considering themselves unsuitable for being part of a group are determined by the types of discrimination and a universal and exclusive vision practised by heterosexuals, who, according to the participants, tend to define homosexuals by confining them to a fixed social category. As F. reported: "Well, I attended absolutely normal state schools and I can say that in general I felt reasonably good about them. When you're in primary school, 
obviously you are more carefree and innocent; you still don't understand the difference between homosexuals and heterosexuals. Apart from that, I already understood that I preferred boy ... I envied the girls because I wanted to be like them. All in all, I can state that I had a good childhood in primary school. Certainly there were those who mocked me for being effeminate but more so for my obesity. However, in lower middle school the story changed. Obviously with adolescence there was a greater awareness, so even my homosexuality was more noticeable, and consequently I was more easily teased by the other boys, although not that much. So I can say that I got through those three years reasonably well. The only negative thing, which also made me suffer a lot, were the remarks made by two teachers, the French teacher and the physical education teacher. Basically they insisted that I behave more like a man and not like a sissy, and told me not to suck up to the other boys. This really upset me a lot. I definitely thought that they talked about me behind my back, and about my veiled homosexuality" (F., gay male, aged 23).

The lack of communication in the educational environment due to the hearing disability, coupled with the schools' incapacity to make deaf children feel at home (often due to the absence of a learning support teacher), is aggravated by the perception of the real or presumed homosexuality of the deaf people interviewed. From the analysis of the data it turns out that, in fact, the mainstream schools appear unready to handle hearing disabilities, and do not provide support regarding non-orthodox sexual choices. F. declared: "My teachers in the normal school always tried to teach me something; they were generally kind towards me. One or two were strict in the right way. For example, my speech therapist helped me to learn to speak correctly from when I was very young, even if I did not understand the exact meaning of every word, nor the sense of some of the Italian sentences. There was just one professor who was different. It was the Italian language teacher whom I never understood: when he tested me in front of the class it was awful; nobody ever seemed to realize that for me, as for other deaf pupils, it was impossible to read his lips due to his defective jaw. I never knew how to express my discomfort, nor explain where the communication problem resided. Therefore, I stayed as silent as possible, trying to avoid discussing any subject with the teachers. I had one teacher, though, in the lower middle school, the art teacher, who always encouraged me.... this disturbed me a lot because of the condition I was in, to imagine myself projected into a future where I taught normal hearing pupils seemed to me a surreal image. For that teacher nothing was impossible, but even if she knew about the potential of deaf persons, she never mentioned this to me. Still, everything that the adults could do outside of 
school was a utopia for me. But the teachers at my special school were completely different; they were lots of fun (apart from the most serious professors); they talked about everything and so, little by little, I managed to voice my thoughts, and my opinions, and above all I learnt how to take part in the group discussions when I felt like it. I managed to master the Italian language reasonably well from the very first day of upper middle school. Until then, even up to a few months previously, I could not construct a decent sentence" (gay male, aged 26).

To be specific, the gender roles (especially masculinity) are often defined more by their distance from rather than desire for something; to learn to be a man means learning not to be feminine, and to be careful, even within the context of explicit male complicity (peer groups, college mates, barrack talk, etc.) to dodge and exorcise every doubt that could ever arise regarding one's own sexual orientation (which reveals itself by the adoption of a crude and vulgar vernacular, knowing how to treat girls, showing oneself to be tough, and by avoiding every possible association with femininity, both in appearance and behaviour). This is often rendered, as we have already seen in the various extracts, in the ritualization of homophobic behaviours in an exaggerated manner, while at the same time distancing oneself from every possible association with homosexual behaviour (negatively sanctioned in the various social contexts) and proclaiming a pronounced hostility towards homosexuals through public declarations (judged positively by the peer group and the social-cultural context) of their own heterosexual identity (Rinaldi 2012). These traits seem to degrade and stereotype all those individuals, whether male heterosexual or homosexual, who do not possess them - such as any individuals who deviate from social norms and from those values linked to the male sex. Violence in all its forms becomes a socially accepted phenomenon. One could additionally mention circumstantial factors, such as the existence of group norms which seem to justify explicit expressions of violence (including sensation seeking, the need to achieve a status and maintain it or to get a masculine reputation). In these cases, the victims are not just homosexuals but all those people who are thus interpreted through that cognitive and categorical filter.

The condition of deafness can also be associated with the stigma linked to gender roles and homosexuality. Let us consider the case of bullying in school: if adolescents realize that there will be no negative consequences or punishment for their actions, it is more likely that they will go 
ahead and also repeat the bullying; with all the more reason to do so if the victim is also stigmatised by deafness.

We should also consider how these processes influence one another and intersect with other subordinate dimensions. When we take into account the relationship between the genders (and specifically masculinity) and sexuality and dis/ability, these last two elements are often considered a social-cultural oxymoron, as disabled people are constantly desexualized and infantilized. They are not expected to have sexual agency, especially homosexual agency. Their environmental context, with its rules and its hierarchy of bodies, genders, sexuality and desires, becomes the primary benchmark for comparison. Also people with disabilities (like elderly people) are desexualized. In the past, the common term for the disabled in Italian was "minorato" which has a common linguistic root with "minore" (infant). Victimization forms must therefore be considered with an eye to potential identity overlaps and consubstantiality.

One of our interviewees clearly sets out the dynamics and the context of the victimization she was subjected to as a deaf, female and lesbian person, at school and within her peer group: "From my perspective, my normal-hearing classmates were abnormal. I would tolerate everything they put me through both bad and good, because until I turned 25 I was unable to stand up for myself and say "no"! Most of my normal-hearing peers seemed to think it was a piece of cake for me and would speak really fast all the time, yet I never got what they were saying. I never understood any of their sentences. We would communicate through body language, looks and gestures on a daily basis. They would take advantage of me sexually and I never liked it, as I only had eyes for the girls. In girls, I secretly looked for the tenderness and kindness of being human" (S., lesbian, aged 19).

It is in the educational context of secondary school, which coincides with adolescence, that so much persecution and violence occurs. A. reports that "at primary school I was completely carefree with the other girls and even in middle school I never felt the burden of being deaf. The problems started at secondary school; I remember that my classmates used to tease me, and slandered me behind my back, and never missed a chance to use me as a scapegoat. I could never understand what was happening around me, because normal-hearing people spoke fast, in fact they whispered a lot, and I never had any way of defending myself. Often they took me by surprise, which put me at an additional disadvantage. With regard to the girls, I was very keen on some of my classmates 
who were really pretty, but I never revealed this. I also had my eye on a female teacher. At the time I had no idea that there could be loving relationships between members of the same sex. I had never encountered the words lesbian, homosexual, or gay; nor had I ever met a homosexual; for these reasons I felt myself to be different and unique - basically abnormal" (A., lesbian, aged 20).

The victimization mechanisms consistently reported across the various interviews lead us to hypothesize, in general terms, that the group of LGBT deaf subjects represents a social target with an increased perception of risk and insecurity. It should be noted, however, that even though the rate of victimization is relatively low, as is the exposure to risk, the dimension of vulnerability, understood as the ability to defend oneself and to support the consequences deriving from victimization, is felt much more deeply also by our interviewees. Even though these subjects tend to react badly, at least cognitively, to the defenceless "deaf" stereotype, their capacity to cope seems rather limited if they are additionally burdened by the stigma of homosexuality. It is also a matter of understanding how the fear of being victimized can be seen as a sort of "indirect victimization," because such fear has repercussions for those who may not have actually suffered any persecution but are fearful of this happening. This arouses real fears that are activated in the daily life of the LGBT deaf, which determine both physical and emotional reactions. The issue of violence towards disabled people, let alone that of their ill-treatment by their families, is always underestimated and underrepresented in the political sphere, the mass media, research and public opinion. This cannot be exclusively attributed to the reticence felt by the victims in reporting discrimination (even though reticence is prevalent enough) but rather can be interpreted by the notion that violence towards the disabled (especially women and LGBT individuals) is a legitimate and accepted violence, which corresponds to the context of relationships between "normal" people. The greatest risks of victimization for these types of violence and offences are often found in places, environments and relationships which are thought to be safe, such as the victim's domestic, family and work environments. Violence towards disabled LGBTs can be conceptualized as normalized violence in that it perfectly mirrors historical and cultural practices that define the relationship between dominant structures and those they oppress. In this sense, deaf LGBT people could be considered designated cultural victims, as the data clearly spotlight the construction of the deaf LGBT individual as a cultural "target" and reveal the workings of power that underlie the roles of gender, physical ability (able-bodiedness) and heterosexuality. 
These aspects are further brought to light by G.'s account: "My normal-hearing schoolmates were the same age as me, whereas the other deaf students were not. So the good relationships I had with my deaf schoolmates were always silent; generally we preferred to play together in various ways, so as to get to know each other better, rather than just have random conversations. By contrast, the bad relationships I had with my normal-hearing peers were very stressful: I can still remember how I lived in fear (now I realize this fear was unjustified as I was only 9 at the time) for two whole years, both because I felt condemned by religion for impure acts and because I was afraid of getting pregnant" (G, lesbian, aged 34). This account also focuses on the role religious stereotypes play in the educational settings.

The family relations of the people interviewed seem to be conditioned on the personal level by having or not having parents who were deaf themselves. In this sense, the discovery that their own child is gay or lesbian as a "bewildering" event does not usually facilitate the psychological support needed because there is also a lack of support from the LIS services. "My parents are deaf, as is my aunt. Until I was 25 years old, the actual dialogue between us was a total zero; we only spoke about ordinary day-to-day events. However from the moment I mastered sign language, I managed to have conversations about everything with my relatives, and I also encouraged my parents to express themselves better, especially with me. With regard to my homosexuality, years ago I sent a long letter to my parents in which I told them I was lesbian; however I quickly regretted this longdistance correspondence as I decided it was useless. A few months ago, I came out again at a dinner with them and introduced the special woman of my life. My mother still does not approve, which upsets me a lot. I am looking for Agedo people [Agedo is the Italian association of relatives of gay people, a supportive group] in our area who know how to communicate in sign language" (F., lesbian, aged 25). The path towards the acceptance of one's own homosexuality therefore appears problematic. The process of coming out within the family is felt as a major obstacle and another potential crisis that these individuals could encounter due to their deafness.

The people we interviewed usually have stable relationships with other LGBT deaf subjects (except for one person who has a relationship with a hearing LGBT individual); to search for a partner, they generally use social networks and themed chat rooms; less frequently, they find partners through recreational activities or LGBT associations. Significantly, the deaf LGBT community seems to be engaged in an (internal) battle against the prejudices of other deaf people towards their LGBT 
orientation and in an equally difficult "external" battle against the world of heterosexual hearing people and of the hearing LGBT community. As C. said, "I mixed with all sorts of local groups and many other associations and communities all over Italy. Unfortunately, even there you can meet discrimination. It is really a matter of civic education" (C., gay male, aged 24). In a similar vein, $\mathrm{N}$. complained: "Certainly at times it irritates me a lot to see the arrogance of some gays in public areas, as if they want to look down on you, pick holes in you" (N, gay male, aged 26). Most of the interviewees use these motives to justify the need to participate in some type of LGBT association that takes into account the specific difficulties of deaf people; many of them feel that they are discriminated against even inside the LGBT community (in associations, pubs, discotheques, meeting places, etc.).

One request that did emerge both in the group interviews and in the online ones was the urgent need to break down visual communication barriers in educational, relational and institutional settings, so as to raise public awareness about LGBT issues in general: "The institutions in Italy have produced lots of good, well-meant advertising and made many promises, but when it comes down to facts, we are failing to deliver on those promises. And this is just the tip of the iceberg, because for us deaf people things are even worse; we feel like downright third-class citizens, ranking after immigrants and homosexuals in the eye of the establishment. It is paramount that we break down every possible visual communication barrier!" "We need to bring down all communication barriers. I want to find a designated help desk in every public institution with people behind it who are specifically trained to communicate with deaf people. In every school there should be a 'sexual orientation' class and a 'history of homosexuality/heterosexuality' class, and these subjects need to be appropriately taught to deaf people by using plenty of images" (L., lesbian, aged 24).

\section{Conclusions}

The insights and reflections set out in the initial part of the paper were intended to introduce and examine the topic of multiple discrimination, emphasizing how disability and homosexuality can constitute factors which increase the risk of victimization. We observe how femininity and disability are both considered indicators of "passivity" and how, for example, the dis/abled male (homosexual) might be doubly discredited as an inadequate male - first, for his disability, and second, for his homosexuality. The perception by society at large of the dis/abled as infantile and 
desexualized needs to be challenged, together with the normative and normalized aesthetic messages sent out by LGBT communities.

Families, social workers and teachers do not seem to have the knowledge and tools necessary to help disabled people emancipate themselves in terms of their sexual agency, and so far other institutions have failed in providing guidance. Even the topic of sexual education should by itself trigger a reflection on diverse issues that should really be looked at in much greater depth. We need to take stock of the fact that dis/abled people (as well as minors and elderly people) have sexual agency and are able to develop gender and sexual cultures. This is an argument bursting with theoretical and hermeneutic potential, but still not really touched on in Italy, as the society has not yet divested itself of moralistic implications and taboos that hinder an in-depth analysis of this phenomenon.

Another important concern is related to the need for specific policies and interventions. For example, school classes and everyday interactions still often reinforce winning models and standards of (hetero)sexuality. Sex is still defined as principally for reproductive purposes and abstinence is valorized. If the disabled are referred to at all, they are defined as "dysfunctional" and therefore unable to guarantee the reproduction of the "standard." Sex education understood in holistic terms should spur a reflection on the ways the dis/abled, elderly, young and very young people can take part in the education process, on the quality contents of the training of future educators, and on what is meant by "empowerment" (who strengthens and emancipates whom or what, and does this not make one suspect staunch but subtle forms of paternalism?). The present formative and educational policies reproduce and maintain the inequalities and the iniquities that characterize social life.

Regarding sexuality in general, and specifically in Italy, we observe the absence of the most basic vocabulary regarding sexual rights, and we are concerned about the way the policies of institutional training reproduce gender roles and conventional dichotomies, gender hierarchies, as well as corporeal and ethnic/racial stratifications of sexuality. We need to start considering ourselves as active participants in the debate about sexuality, rather than mere receivers of imposed interventions outside our own capacities to negotiate and create sexual meanings. The less able ("minorati"), understood as pre-sexual or non-sexual infants, make the roles and the objectives of 
sex education rather problematic. The problem can be traced to the educators' inability to imagine every social category as composed of incorporated sexual individuals, and to the clumsy attempts to suppress information about the standardization and therefore about the "normalization" of a process of generic psycho-social-sexual development. If information is made available, it is decontextualized and often complicit with those same services (social, prevention, training, etc.) which programme, orient and define sexuality yet do not comprehend the space of sexualities. Therefore policy makers, researchers, social workers and all those who plan, evaluate and implement policies, operations and services should be aware that these processes have effects and social consequences: to single out some categories and certain stages of development is to effect symbolic violence, even if involuntary. To indicate one form of sexuality as more worthy of recognition means both implicitly and explicitly contributing to the spread of "acceptable" and "shareable" representations from which institutions, services, social workers, nurses, doctors, politicians and psychologists can draw conclusions as to which subjects are more worthy of these measures, services and policies. What are the real-life effects of sexual education measures related to non-normative sexual identities and sexual, gender, race and class inequalities? Will the result be the emancipation of these subjects or the creation of new forms of normalization with a view to constructing new "user" categories? We need to be mindful of the fact that every sexual education measure introduced is, at the end of the day, a political decision, because it implies a conflict between different (and often opposing) political powers on a specific policy.As suggested by Alldred and David, specific meanings and workings of power are thus established (Alldred and David 2007, 13).

\section{Works Cited}

Alldred, Pam and Miriam E. David, M.E. Get real about sex. The politics and practice of sex education, Maidenhead and New York: Open University Press/McGraw-Hill, 2007. Print.

Anzaldúa, Gloria. Borderlands/La Frontera: The New Mestiza, San Francisco: Aunt Lute Books, 2007. Print.

Bersten, Rosanne. "Marginalia: living on the edge", Gay and Lesbian Issues and Psychology Review 4.1 (2008): 9-18. Web. 23 Aug. 2015.

Cramer, Elizabeth P., and Stephen F. Gilson. "Queers and crips: Parallel identity development processes for persons with invisible disabilities and lesbian, gay, and bisexual persons", Journal of gay, lesbian, and bisexual identity 4 (1999): 23-37. Print.

Goffman, Erving. Stigma: Notes on the Management of Spoiled Identity. Englewood Cliff, N.J.: 
Prentice-Hall, 1963. Print.

Goffman, Erving. Relations in Public: Microstudies of the Public Order. New York: Basic Books, 1971. Print.

Ingraham, Chris. (ed.). Thinking Straight: The Power, the Promise and the Paradox of Heterosexuality, New York: Routledge, 2005. Print.

McRuer, Robert. Crip Theory: Cultural Signs of Queerness and Disability, New York: New York University Press, 2006. Print.

Muñoz, José Esteban. Disidentifications: Queer of Color and the Performance of Politics, Minneapolis: University of Minneapolis Press, 1999. Print.

Murray, Stephen, "The Institutional Elaboration of a Quasi-ethnic Community", International Review of Modern Sociology 9 (1979): 165-178. Print.

Rinaldi, Cirus. "Analizzare ed interpretare I'omofobia: eterosessualizzazione, costruzione delle maschilità e violenza antiomosessuale," Alterazioni. Introduzione alle sociologie delle omosessualità. Ed. Cirus Rinaldi, Turin: Kaplan, 2012, 121-163. Print.

Thompson, S. Anthony, Mary Bryson, and Suzanne de Castell. "Prospects for Identity Formation for Lesbian, Gay, or Bisexual Persons with Developmental Disabilities." International Journal of Disability, Development and Education 48.1 (2001): 53-65. Print.

Warner, Michael (ed.). Fear of a queer planet. Queer politics and social theory, Minneapolis: University of Minnesota Press, 1993. Print. 